\title{
Insights into Activity-Dependent Map Formation from the Retinotectal System: A Middle-of-the-Brain Perspective
}

\author{
Edward S. Ruthazer, Hollis T. Cline \\ Cold Spring Harbor Laboratory, Cold Spring Harbor, New York 11724
}

Received 1 July 2003; accepted 30 August 2003

\begin{abstract}
The development of orderly topographic maps in the central nervous system (CNS) results from a collaboration of chemoaffinity cues that establish the coarse organization of the projection and activity-dependent mechanisms that fine-tune the map. Using the retinotectal projection as a model system, we describe evidence that biochemical tags and patterned neural activity work in parallel to produce topographi-
\end{abstract}

The idea that sensory maps in the central nervous system (CNS) achieve basic topographic order through molecular guidance cues and are refined to mature levels of precision by activity-dependent mechanisms has emerged over the past half-century as a textbook truism in developmental neurobiology, despite a lack of direct evidence in many systems. This may be explained in part because of the overwhelming strength of the evidence for both mechanisms in the retinotectal system.

The concept of molecular determinants of topographic organization is universally accepted for the retinotectal system, due in large part to the pioneering work of Friedrich Bonhoeffer and his colleagues, which provided faces (such as axon repulsion) and names (like "RAGS" and "RGM") for the so-called "chemoaffinity cues" initially proposed by Sperry (Sperry, 1963; Harris and Holt, 1995; Drescher et al., 1997). On the other hand, the specific molecular cues and mechanisms that determine the organization of

Correspondence to: H.T. Cline (cline@cshl.edu) (C) 2004 Wiley Periodicals, Inc.

DOI 10.1002/neu.10344 cally ordered axonal projections. Finally, we review recent experiments in other CNS projections that support the proposition that cooperation between molecular guidance cues and activity-dependent processes constitutes a general paradigm for CNS map formation. () 2004 Wiley Periodicals, Inc. J Neurobiol 59: 134-146, 2004

Keywords: topographic; ephrin; retinotectal; ocular dominance; retinogeniculate; thalamocortical sensory maps in other parts of the CNS, most notably primary sensory cortex, have until recently remained mostly faceless and nameless. Consequently, in these brain regions, activity-dependent aspects of map formation have won out in the competition for the attention of most investigators. Building upon the theoretical framework established by Hebb (1949), researchers and theorists have demonstrated that activity-dependent mechanisms play a necessary, if not sufficient, role in many aspects of the development of functional organization in sensory maps (Katz and Shatz, 1996).

Because of their different perspectives and experimental approaches, a gap, more philosophical than empirical, may have emerged between experimenters who view development in terms of biochemical mechanisms and those who see activity-dependent processes as the key to map formation. In recent years, a number of prominent experiments using new technologies to provide a finer level of anatomical analysis or greater control over molecular manipulations than previously possible have helped narrow this gap. These experiments collectively reveal that cooperation between biochemical and activity-dependent mechanisms is likely to be the rule rather than the 
exception in CNS map formation, and that many developmental events once attributed specifically to activity-dependent or molecular guidance mechanisms in fact contain demonstrable components of each.

The objective of this review is to examine, using the retinotectal projection as a model, how chemoaffinity cues and patterned neural activity collaborate in the establishment and refinement of precise sensory inputs throughout the CNS. We have chosen to focus primarily on axon morphology because it is the earliest framework upon which topographic connections are built.

\section{RETINOTECTAL PROJECTION}

\section{Mechanisms of Chemoaffinity}

More is known about the molecular basis for topographic mapping of retinal ganglion cell (RGC) axons from the eye onto the optic tectum in the CNS than for any other sensory projection. Roger Sperry first proposed his "chemoaffinity hypothesis" as a result of his now classic studies on the regenerating retinotectal projection in goldfish and frogs (Sperry, 1963). His experiments showed that after optic nerve section, RGC axons regenerate to their normal topographic positions in the tectum, regardless of whether the entire retina is present (Attardi and Sperry, 1963) or whether the eye is rotated prior to reinnervation (Sperry, 1944). These experiments suggested the existence of biochemical labels for the specification of axon-target interactions and provided the conceptual basis for the work of Friedrich Bonhoeffer and others that ultimately led to the identification of specific molecular guidance factors for retinotectal topography.

A combination of in vitro and genetic studies have revealed that the mapping of RGC axons along the anterio-posterior axis of the optic tectum is controlled in large part by the matched gradients of EphA receptor tyrosine kinases in the retina (temporal retina $>$ nasal retina) and the ephrin-A family of Eph ligands, particularly ephrin-A2 and -A5, in the tectum (caudal tectum $>$ rostral tectum) (McLaughlin et al., 2003). Activation of EphA by their ephrin ligands leads to axon repulsion (Drescher et al., 1997; Flanagan and Vanderhaeghen, 1998) and inhibition of axon branching (Yates et al., 2001). Consequently, axons from RGCs in the temporal retina, where EphA expression is high, are inhibited from innervating the caudal tectum where ephrin-A levels peak [Fig. 1(A)].

Mapping along the mediolateral axis is mediated by interactions between EphB and ephrin-B [Fig.
1(B)]. In contrast to the GPI-linked ephrin-A family, ephrin-Bs are transmembrane proteins, capable of direct intracellular signaling in response to EphB binding (Flanagan and Vanderhaeghen, 1998). EphB/ephrin-B interactions appear to mediate axon attraction, rather than repulsion, both through EphB and ephrin-B signaling (Hindges et al., 2002; Mann et al., 2002). EphB and ephrin-B form complementary gradients in both the retina and tectum. It has been shown in mice that the relative enrichment of EphB in ventral retina contributes to axon targeting to the medial part of the superior colliculus where ephrin-B levels are high (Hindges et al., 2002). In Xenopus, high levels of ephrin-B in dorsal RGCs have been shown to guide axons to the EphB-rich ventral tectum (Mann et al., 2002).

These elegant models for biochemical mapping of topography are complicated by two issues. First is the question of why nasal RGC axons, which have low levels of EphA expression, are not free to innervate all tectal sites equally. The restriction of axons from the temporal retina to the rostral parts of the tectum is consistent with the observations in vitro of EphAdependent inhibitory interactions mediated by the high levels of eprhin-A in caudal tectum. Curiously, the nasal axons, which show no preference for caudal tectal membranes in in vitro assays (Walter et al., 1987), nonetheless selectively form highly organized projections to the caudal tectum that, like temporal axons, are severely disrupted in ephrin-A knockouts. Second, contrary to the simplest formulation of Sperry's chemoaffinity hypothesis, the termination zones of RGC axons are not determined by absolute levels of Eph signaling. This was demonstrated in a clever experiment using transgenic mice in which EphA3 expression was up-regulated in a subset of RGCs scattered across the retina (Brown et al., 2000). This elevated EphA3 expression together with the normal temporal-to-nasal gradient of EphA receptor expression resulted in a double retinotopic projection to the tectum. The EphA3 over-expressing RGC axons, presumably repelled by the ephrinA in the caudal tectum, formed a compressed map in rostral tectum, while the remaining RGC axons formed a compressed map in the caudal tectum. These data challenge any simple dose-response model for the repulsive interaction between EphA- and ephrinA-expressing cells because they suggest that individual axons are influenced by the levels of EphA in the axons of other cells that terminate in far removed sites in the tectum.

Both of these issues may be explained by the proposal that RGC axons compete for available target space (Fraser and Hunt, 1980; Boss and Schmidt, 1984; Feldheim et al., 2000). Furthermore, such a model is supported by early experiments in which 


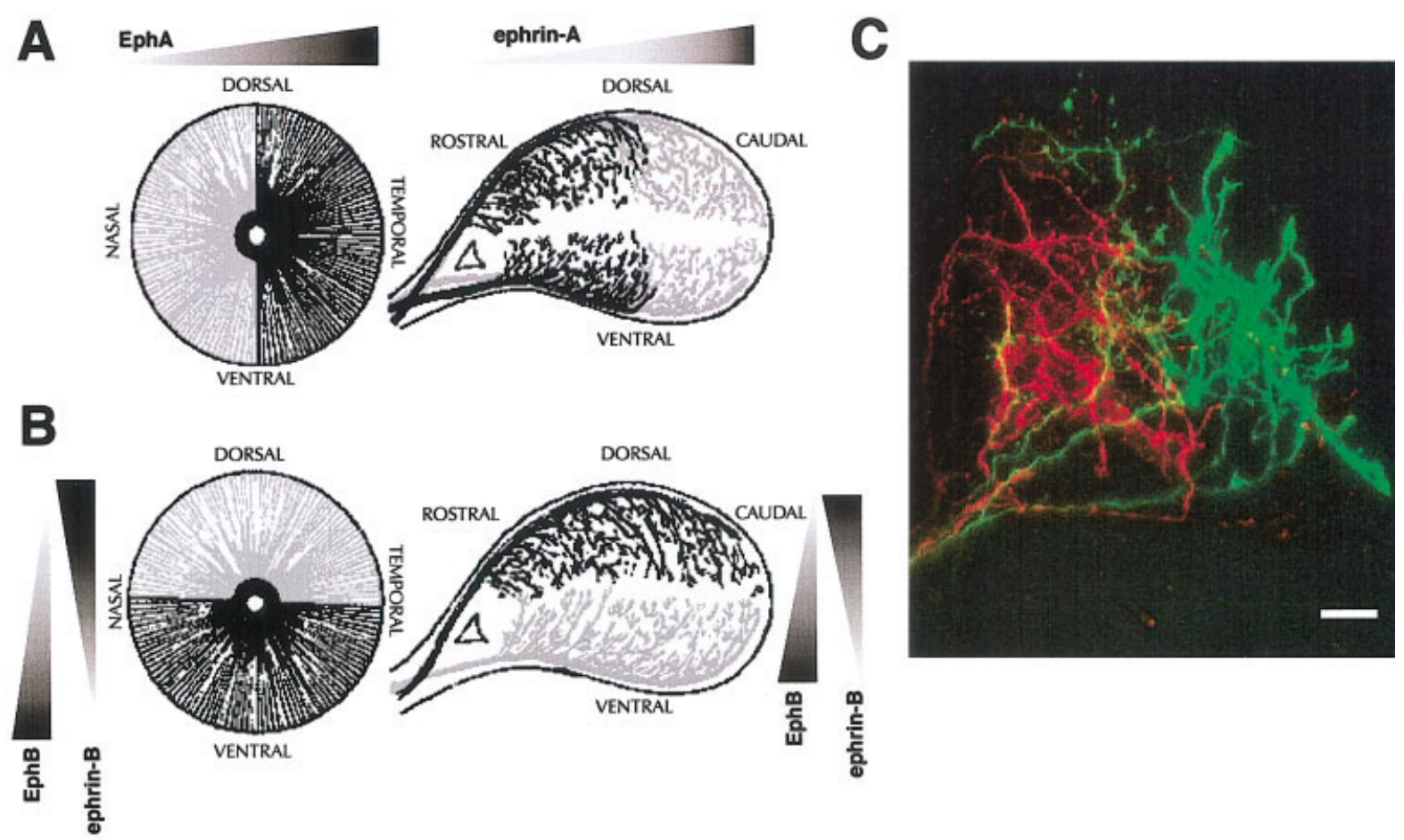

Figure 1 Chemoaffinity cues in the retinotectal projection. Connectivity observed in Sperry's original studies of regenerating goldfish retinotectal fibers originating in retinal halves (Sperry, 1963). Black regions of the retina project to black sites in the tectum, and likewise, gray projects to gray. (A) Ephrin-A and the EphA receptors act as chemoaffinity molecules for rostrocaudal mapping in the optic tectum. (B) Ephrin-B and EphB signal dorsoventral mapping. The graded distributions of ephrins and Eph receptors are indicated next to their appropriate structures. (C) Retinotopic organization of inputs imaged in the optic tectum of a live Xenopus tadpole. Temporal and nasal retina were labeled, respectively, with diI (red) and FITC-dextran (green). Orientation as in (A). Scale bar $=20 \mu \mathrm{m}$. Panels (A) and (B) are adapted from Sperry (1963).

ablation of large areas of the retina or tectum prior to reinnervation resulted respectively in expanded or compressed topographic maps (Schmidt et al., 1978; Finlay et al., 1979; Udin and Gaze, 1983; Schmidt, 1985). In vivo imaging experiments in Xenopus tadpoles also provide evidence that RGC axons preferentially extend into sparsely innervated territory (Ruthazer et al., 2003). One hypothetical mechanism by which this could occur is suggested by the observation that most retinotectal axon branch initiation takes place at sites where synaptic structures are present (Alsina et al., 2001). Thus, it is possible that postsynaptic dendrites can induce axonal backbranching by actively contacting the axon for synaptogenesis (Ziv and Smith, 1996). In this case, the availability of postsynaptic partners would be rate limiting for axon branch addition in vivo. However, this competition for available space probably does not require neural activity, as it is not prevented by intraretinal tetrodotoxin (TTX) injections (Olson and Meyer, 1994; Meyer and Wolcott, 1988) or inhibition of $N$-methyl-D-aspartate receptors (NMDARs) in the superior colliculus or optic tectum (Huang and Pallas, 2001; Ruthazer et al., 2003).

\section{Role of Neural Activity}

Numerous experiments suggest that patterned neural activity probably does not play an essential role in establishing the global topography of the retinotectal map, but is critical for the local refinement of the projection. TTX injections into the eyes of developing chick (Kobayashi et al., 1990) or zebrafish (Kaethner and Stuermer, 1994) or in goldfish during RGC axon regeneration (Meyer, 1983; Olson and Meyer, 1991) do not prevent the establishment of crude retinotopic organization of RGC afferents in the tectum. In an imaginative set of experiments, Harris grafted axolotl eyes into Taricha torosa newts, a species that naturally synthesizes TTX but is itself insensitive to the toxin. The transplanted eyes were unable to generate action potentials in this environment, but nonetheless formed a topographically organized projection to the 
tectum, even in competition with the endogenous unblocked axons (Harris, 1980).

In contrast to coarse topography, the convergence, or point-to-point connectivity, of the retinotectal map is profoundly impacted by manipulations of neural activity. Small focal injections of neuronal tracers into the retina label individual or small groups of retinotectal axons that project to a restricted area of the tectum. Blocking retinal activity by TTX injections into the eye results in enlarged termination zones of labeled axons both in developing (Kobayashi et al., 1990) and regenerating projections (Olson and Meyer, 1991) and a corresponding enlargement of electrophysiologically measured receptive fields (Schmidt and Edwards, 1983). Although results in the developing and regenerating retinotectal projections have generally arrived at similar conclusions, these systems differ in many important ways. It is unlikely that the same compliment of signaling molecules that are responsible for normal development is present in the regenerating projection (Grant and Tseng, 1986; Udvadia et al., 2001). In addition, regenerating axons reinnervate the tectum with less initial order than that seen in normal development (Rankin and Cook, 1986; Stuermer, 1988). It is therefore essential to confirm results from the regenerating projection in the context of normal development. In developing zebrafish larvae mutant for the gene macho, sodium currents are reduced on days 5 and 6 postfertilization when RGC axons are actively remodeling their projections to the tectum (Gnuegge et al., 2001). Individual RGC axon arbors are enlarged in macho mutants compared with wild-type controls. Similarly, in mice lacking the beta-2 subunit of the neuronal nicotinic acetylcholine receptor, which lack normal patterns of early spontaneous retinal activity, retinocollicular typography is grossly abnormal (McLaughlin et al., 2003).

Blocking NMDARs in the postsynaptic tectal neurons similarly decreases retinotopic precision of the RGC afferent innervation (Cline and ConstantinePaton, 1989; Simon et al., 1992) without the concomitant increases in axon arbor area seen with TTX treatment (Reh and Constantine-Paton, 1985). This finding indicates that the postsynaptic neurons play an important role in this process, and implies that an activity-dependent retrograde signal may be generated postsynaptically that influences presynaptic axon morphology. It also falsifies the simplistic argument that the failure of maps to refine under activity blockade might be due entirely to a nonspecific expansion of electrically silenced axon arbors, and instead suggests that neural activity may play an instructive role in organizing the map. Powerful support for the idea that the correlation structure of visually-driven neural activity is important to the refinement of the retino- tectal map comes from the demonstration that both anatomically reconstructed axonal arbors and electrophysiologically measured multiunit receptive fields fail to refine normally in animals reared under stroboscopic lighting conditions that artificially increase the correlation of inputs across the retina (Schmidt and Buzzard, 1993).

\section{Eye-Specific Bands}

The most compelling evidence that neural activity participates instructively in retinotectal map formation comes from experiments in which unique patterns can be demonstrated to alter the map in a predictable manner. The optic tectum normally receives input exclusively from the contralateral eye in frog tadpoles. However, several experimental manipulations can result in dual innervation of a single tectal lobe by two retinae. For instance, if an additional eye primordium is grafted onto a frog embryo it will develop into a functional third eye and jointly innervate the optic tectum together with the native contralateral eye (Constantine-Paton and Law, 1978). Under these circumstances, both eyes express identical sets of chemoaffinity molecules and thus should be driven to form overlapping retinotopic maps. Interestingly, however, the afferents from the two eyes segregate into discrete eye-specific termination zones, also known as ocular dominance bands. This observation is important for two reasons: first, it confirms that chemoaffinity is not the sole force controlling retinotectal map organization, for it is exceedingly unlikely that chemical tags for ocular dominance bands exist in the normally monocular frog tectum. Second, because the two eyes are molecularly indistinguishable from one another, it must be the differences in the patterns of activity in the two eyes that distinguish their respective afferents. In general, manipulations that cause RGC axons expressing common molecular cues to have different patterns of activity will result in afferent segregation. For example, if axons from both eyes in an animal are made to project to a single tectal lobe by rerouting axons from one eye to innervate the ipsilateral tectum, ocular dominance bands form as well (Straznicky and Glastonbury, 1979; Law and Constantine-Paton, 1980). Surgically manipulating a single eye to create a bilaterally symmetric double nasal or double temporal retina similarly produces segregation of axons from the two halves of the eye (Ide et al., 1983; Coletti et al., 1990).

Evidence that these two sets of inputs sort on the basis of differences in their neural activity comes from experiments in which afferent activity was blocked by application of TTX in the eye during regeneration of the retinotectal projection (Meyer, 
1982; Boss and Schmidt, 1984). Chronic TTX treatment not only prevents the segregation of inputs from taking place in regenerating projections, but when applied to segregated maps is able to desegregate existing ocular dominance bands (Reh and Constantine-Paton, 1985). Importantly, the maintenance of segregated eye-specific bands also requires postsynaptic NMDAR activity. Chronic application of APV to a binocularly innervated tectum desegregates its eye-specific bands, and removing NMDAR blockade permits the bands to segregate again (Cline et al., 1987). Furthermore, the initial segregation of eye specific bands also requires NMDAR transmission, as demonstrated by time lapse imaging of segregating inputs during the early development of ocular dominance bands in tadpoles (Ruthazer et al., 2003).

\section{Correlation-Based Mechanisms}

These findings provide important insights into the mechanisms of activity-dependent retinotectal map refinement. The requirement for NMDAR activity, both in the fine-tuning of normal retinotopy and in the segregation of retinotectal ocular dominance bands, suggests the existence of a correlation-based, or Hebbian, mechanism for fine-tuning axonal inputs based on their patterns of activity (Hebb, 1949; Stent, 1973). Because the magnesium block of NMDAR transmission is relieved when a cell is depolarized by excitatory inputs at its other synaptic sites, NMDARs can act as molecular detectors of correlation in firing between pre- and postsynaptic partners, as well as detectors of coactivity of multiple inputs to a cell. RGCs from nearby locations in the retina will respond to visual stimuli with greater temporal correlation in their firing patterns than will RGCs from distantly separated sites in the retina or from two different eyes. The convergence of correlated neighboring RGC afferents onto a tectal neuron is more likely to activate NMDARs. On the other hand, a mismatched axon will fire out of synchrony with the other inputs to its postsynaptic cell and thus fail to strongly activate NMDARs and their downstream signaling cascades. By analogy to the NMDAR-dependent phenomena of LTP and LTD, which have been reported in the $X e$ nopus retinotectal pathway (Zhang et al., 1998), strong activation of NMDARs would strengthen and stabilize synapses, whereas weak NMDAR activation would have the opposite effect, possibly leading to synapse elimination.

Early evidence that retinotectal axons are highly dynamic structures came from studies of the shifting projections between the retina and tectum in fish and frogs (Easter and Stuermer, 1984; Reh and Constantine-Paton, 1984). Because the eyes add new cells radially at the marginal zone in the peripheral retina, forming a ring of neurogenesis, but the tectum grows linearly by adding cells at its caudomedial proliferative zone, the axonal inputs to the tectum must continually shift to maintain normal retinotopy to compensate for the mismatch in the axes of growth of these two structures. Time lapse imaging experiments further revealed that RGC afferent axons add and retract many branches in the tectum over a time course of several minutes (Kaethner and Stuermer, 1992; O’Rourke et al., 1994; Witte et al., 1996). Thus, the dynamic rearrangements of axonal branch tips must participate in map formation through the regulation of axon morphology. At the level of the individual axon, neural activity could influence map refinement and segregation in any of three ways. Neural activity could: regulate axon elaboration locally; selectively stabilize axonal branches; and cause branch elimination from inappropriate sites (Fig. 2).

In vivo time lapse imaging of individual axons in fish and frogs has helped clarify the details of the process by which arbor refinement proceeds. Blocking activity with TTX or APV in Xenopus tadpoles during development has been shown to enhance rates of both branch addition and retraction (Cohen-Cory, 1999; Rajan et al., 1999). These observations suggest that normal levels of neural activity in part serve to constrain axon branch initiation. They also support the idea that neural activity contributes to the stabilization of individual axon branches, as branch tip retractions increase when activity is blocked. However, these observations alone cannot determine whether activity merely alters the overall rates of axon branch rearrangements that are governed by other factors, or actively participates in sculpting the arbors by regulating the balance of branch tip addition and elimination. In the regenerating monocular projection in goldfish, severely mistargeted axons are more commonly observed than in normal development, permitting a comparison of behaviors within and outside the normal termination zone. In contrast to axons in their appropriate termination zones, mistargeted axons were found to have relatively higher rates of retraction, and activity blockade actually reduced retraction rates for these axons (Johnson et al., 1999), raising the possibility that stray axons might be actively eliminated.

The fact that ocular dominance bands are able to resegregate after recovery from NMDAR blockade (Cline et al., 1987) in fact requires that some form of NMDAR-dependent branch elimination does occur. The dually innervated tectum constitutes an extreme case of correlation mismatch between axons that project to the same site in the tectum. Thus the same mechanisms that prune and sharpen the normal map will underlie the segregation of the binocular map. 


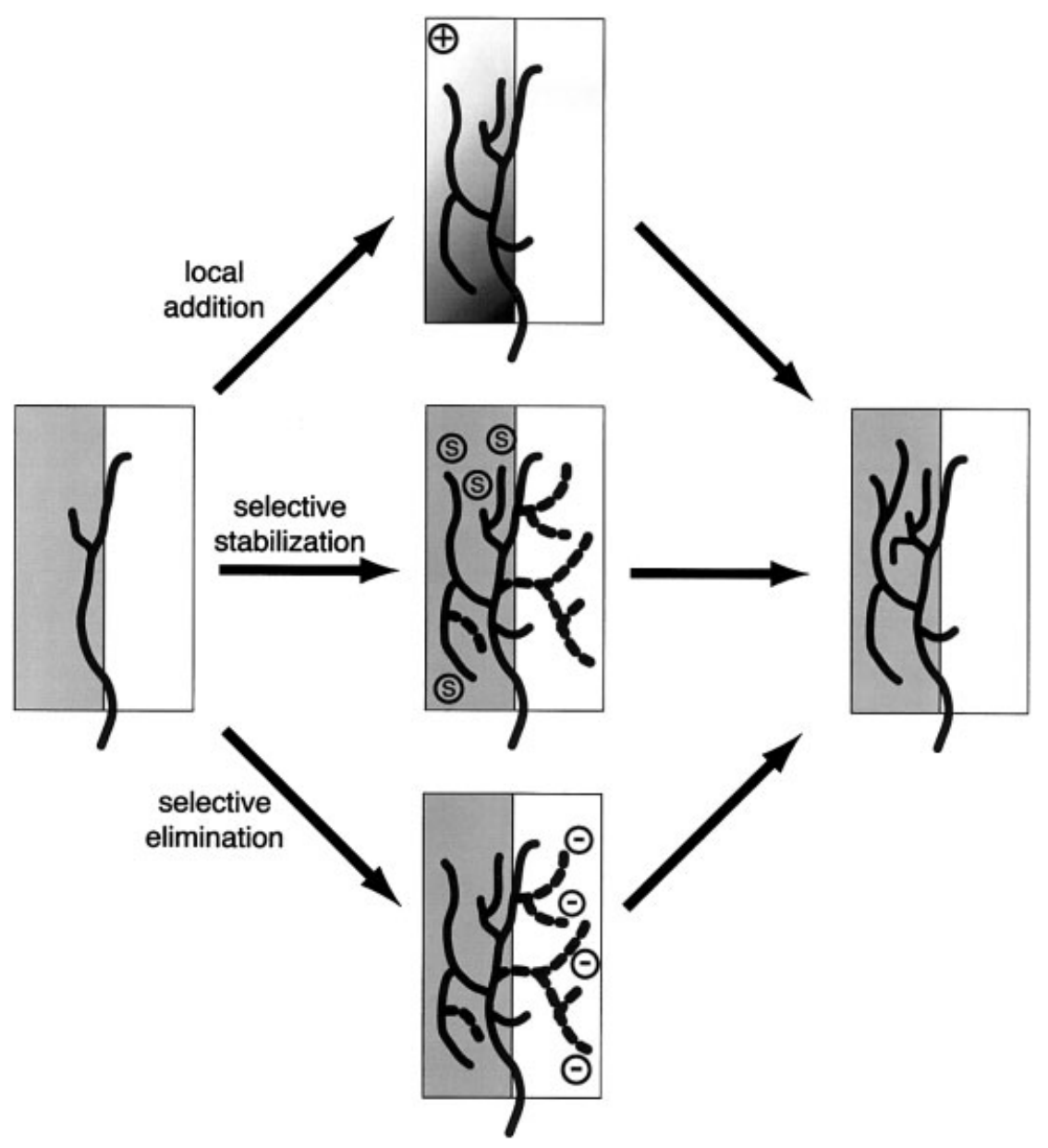

Figure 2 Possible mechanisms for axon branch refinement. An axon is portrayed growing along the border between appropriate (gray) and incorrect (white) ocular dominance territories. The top panel shows local branch induction by a factor released in appropriate territory. The middle panel shows random branch addition with selective stabilization of branches (marked by "s") in appropriate territory. Branches that are fated for future withdrawal are drawn with dashed lines. The bottom panel illustrates active elimination of branches (marked by "-") that form in inappropriate territory. All three mechanisms would result in essentially the same final outcome.

Experimentally, however, the dually innervated tectum provides an opportunity to observe the role of correlated activity independently of biochemical cues. This is because stray axons in the monocular projection will innervate territory where both their activity patterns and their chemoaffinity signals are inappropriate. In contrast, for the binocularly innervated tectum, afferents that project to the same tectal site with identical biochemical tags can nonetheless differ in activity patterns if they originate from different eyes.

Progress on how correlated activity regulates branch dynamics has come from time lapse imaging of the process of eye-specific segregation in dually innervated optic tecta (Ruthazer et al., 2003). Individual RGC axons in binocularly innervated tecta revealed that the rate of elimination of individual branch tips that extended in territory dominated by the oppo- site eye was nearly double that for branches in same eye territory. NMDAR blockade reduced branch elimination rates in opposite eye territory but did not affect, and may even have slightly increased, branch loss from same eye territory, supporting the idea of correlation-based branch stabilization and elimination mechanisms. This study found no evidence for selective branch addition with respect to ocular dominance.

The following scheme is suggested for retinotectal topographic map development (Fig. 3): Chemoaffinity cues guide axon ingrowth and coarsely regulate axon branch additions and retractions, resulting in most but not all branches forming at topographically correct sites. Competition for available target space modulates this process, correctly scaling the retinotopic map to the tectal area. Finally, an activity-dependent LTP-like process selectively stabilizes topographi- 


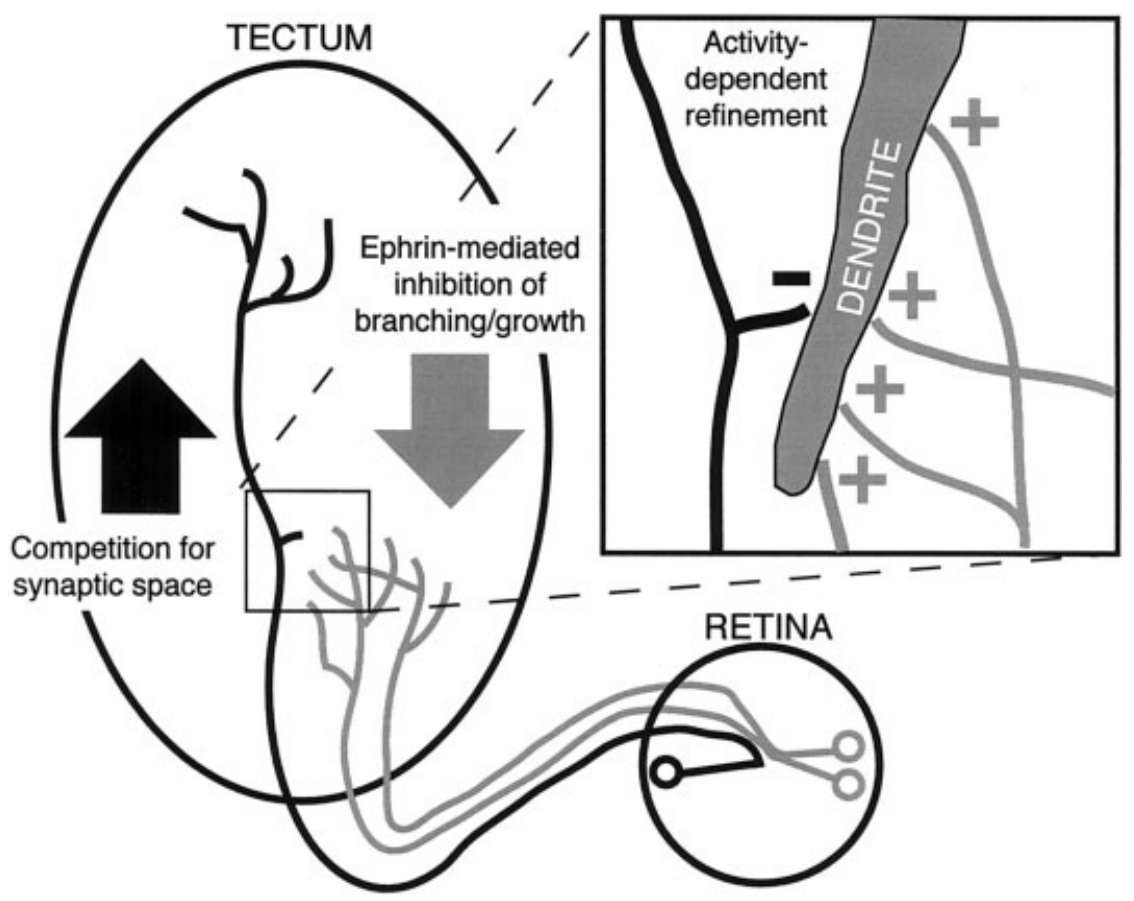

Figure 3 Scheme for retinotopic map formation. At a coarse level of topography, the repulsive or branch inhibitory activity of ephrins exerts a constraint that keeps RGC axons from more temporal parts of the retina from innervating caudal tectum. On the other hand, the proposed competition for limited synaptic space in rostral tectum would make the caudal tectum a preferable target for nasal axons that are not inhibited from growing there. Simultaneously, an axon that attempts to make synaptic contacts in territory where its firing patterns are poorly correlated with the majority of other inputs to the local tectal neurons will fail to make stable connections and will be eliminated while synapses formed by correlated inputs will be strengthened and stabilized (inset).

cally correct branches based on their mutual patterns of neural activity. Inappropriate branches are weakened and eliminated, perhaps through a mechanism analogous to homosynaptic LTD.

The above list is not intended to imply strict temporal order or hierarchy. It is likely that all of these events participate in parallel in structural decisions made by the afferents, at least from the time of synaptogenesis onward. As discussed in detail above, activity is not required for the establishment of crude retinotopy by chemoaffinity mechanisms. However, it is also appears that Eph signaling may not be required for activity-dependent segregation of afferents, as evidenced by the fact that in ephrin-A2/A5 double knockout mice axons labeled from focal injections into the retina form multiple dense clusters, scattered across the rostrocaudal axis of the tectum (Feldheim et al., 2000). Furthermore, the competition for available space is also preserved in these mutants because bulk labeling of RGC axons results in uniform labeling across the entire tectum. Thus, any of these events can occur in the absence of the others, but fail to produce normal maps due to their respective spatial limitations. Gradients of ephrins provide the least information over short distances where activity-dependent mechanisms are most sensitive. Conversely, correlation-based plasticity requires that the postsynaptic neuron compare the timing of inputs, which is prone to temporal distortion and increasingly noisy over large areas. Its range may be limited by the size of postsynaptic dendritic arbors (Katz and Constantine-Paton, 1988) or by factors that constrain signaling within individual dendrites downstream of NMDAR activation (Tao et al., 2001). Interestingly, these constraints can change during development both at the cellular level (Tao et al., 2001) and at the level of circuit modulation such as GABAergic transmission (Ben-Ari, 2002). Finally, a growing body of evidence suggests that chemoaffinity and activitydependent cues, far from being mutually exclusive mechanisms, can interact and modulate each other (Grunwald et al., 2001; Takasu et al., 2002).

\section{BEYOND THE MIDBRAIN}

There is extensive experimental evidence that chemoaffinity and neural activity collaborate for precise 
topographic map formation in the optic tectum, both for the retinotectal projection outlined above as well as for other projection systems in the tectum (for excellent reviews of other projections see Udin and Grant, 1999 and Knudsen et al., 2000). Is the tectal model of cooperation between biochemical tags and correlation-based projection refinement applicable to other brain regions? Experiments over the past decade suggest that the similarities may be greater than previously believed.

\section{Eye-Specific Segregation in the Thalamus}

The segregation of left and right eye afferents into eye specific laminae in the lateral geniculate nucleus (LGN) of the thalamus is a classic system in which the influence of neural activity on axonal morphology has been studied, and the focus of much activity in recent years (Shatz, 1996). Intraventricular infusion of TTX in fetal kittens, during the period of retinal axon segregation, prevents axons from withdrawing from territory serving the opposite eye, resulting in greatly enlarged arbors (Sretavan et al., 1988). Eye-specific layers in the LGN in mammals segregate during a stage of development when the RGCs are not yet visually excitable, and instead rely for stimulation on spontaneous waves of retinal activity (Wong et al., 1993). These waves in the retina are initially driven by cholinergic transmission but later require glutamate (Wong et al., 2000; Zhou and Zhao, 2000). When the waves are pharmacologically inhibited in both eyes axons fail to withdraw from territory that would normally be exclusively innervated by the other eye (Penn et al., 1998). Transgenic mice lacking the beta-2 subunit of the neuronal nicotinic acetylcholine receptor do not develop retinal waves during the early period when their generation requires cholinergic neurotransmission and consequently do not have segregated eye-specific layers in the LGN (Rossi et al., 2001; Muir-Robinson et al., 2002). Interestingly, however, the later glutamatergic waves, which are not prevented in the knockouts, are able to segregate the afferents into many smaller eye-specific patches (Muir-Robinson et al., 2002). The waves provide a mechanism by which both eyes are equally active but unlikely to be synchronously active. Thus, although all the spatiotemporal features of the waves may not be critical (Huberman et al., 2003), when the waves are either blocked or enhanced in just one eye, the more active eye's termination area expands at the expense of that of the less active eye (Penn et al., 1998; Stellwagen and Shatz, 2002). However, in none of the manipulations did axons from the more active eye completely invade the normally monocular seg- ment of the LGN, consistent with the existence of molecular cues that regulate axonal innervation at a coarser scale.

Ephrin-A5 could serve such a role in the LGN. It is expressed in a ventral $>$ dorsal gradient in both the dorsal and ventral nuclei of the LGN (Feldheim et al., 1998). Like its action in the superior colliculus, it contributes to thalamic topography by inhibiting RGCs in the temporal retina from innervating the ventral-most parts of the LGN. Ephrin-A5 knockout mice have severe deficits of LGN retinotopic organization, especially for temporal RGC axons.

The interplay between chemoaffinity cues and activity-driven axonal remodeling in the LGN appears quite similar to that outlined for the retinotectal system. For example, in beta- 2 nicotinic receptor knockout mice, LGN retinotopy is unrefined both anatomically and as measured electrophysiologically (Grubb et al., 2003). However, one important caveat is that NMDAR blockade has not been shown to prevent eye-specific segregation in the LGN, suggesting that fundamentally different downstream signaling pathways could be involved in the activity-dependent mechanisms operating in the LGN (Smetters et al., 1994). It will be informative to identify these alternative signaling pathways.

\section{Cortical Topography}

The mechanisms responsible for establishing topography in the sensory areas of the cortex remain poorly understood, though a number of transcription factors have been implicated in cortical regionalization and thalamic axon targeting (O'Leary and Nakagawa, 2002). The ephrin-A5 knockout appears to have a distorted somatosensory map, but the molecular basis for this abnormality is not clear (Prakash et al., 2000). It is noteworthy, however, that the effects of inhibiting neural activity on topographic organization of the thalamocortical projection are quite modest. Molnar and colleagues have examined topography in a transgenic mouse deficient in SNAP-25, which lacks evoked synaptic transmitter release (Molnar et al., 2002). These animals die at birth, but show no detectable disorganization of thalamocortical topography, as studied by making evenly spaced, focal lipophilic dye injections into cortex. This is consistent with activity-independent molecular specification of cortical topography at the gross level.

Similarly, mice with a targeted cortical knockout of the NR1 subunit of the NMDAR, which lack NMDARs in all excitatory neurons of the neocortex, maintain appropriate topographic order of ventrobasal thalamic inputs onto somatosensory barrel cortex (Iwasato et al., 2000). Interestingly, however, in these 
animals the innervation of individual barrels appears less discretely clustered, and the cortical cells in layer 4 , which normally surround barrel hollows and extend their dendrites inward, fail to develop this morphological feature (Datwani et al., 2002). While these data must be interpreted cautiously, particularly in light of the fact that lesion-induced map reorganization is not defective in these animals, it is plausible that fine-tuning, but not coarse organization, of the map has been affected in these animals.

Intracortical projections are also topographically organized (Salin and Bullier, 1995). This organization is particularly striking in the precision of innervation by interhemispheric connections that link the primary visual cortices on both sides of the brain. In general, callosally projecting axons link sites in the two hemispheres that have overlapping visual receptive fields, though not necessarily at anatomically matched sites in the visual cortex. Interestingly, if both eyes are removed in an animal early in development, prior to the invasion of callosal axons into the cortical gray matter, the map of intracortical connectivity in primary visual cortex is not only less precisely organized, but is actually respecified to connect anatomically rather than topographically corresponding sites (Olavarria and Li, 1995; Olavarria and Hiroi, 2003). Thus, it appears that there may be a default corticotopic connectivity between the two hemispheres that is superceded in normal development to become retinotopic in response to the influence of the eyes, possibly as a consequence of interhemispheric correlations induced by the retinal waves of spontaneous activity. These experiments establish that an orderly map can form in enucleated animals in which activity patterns in the two hemispheres ought not to be correlated, suggesting an activity-independent basis for the crude map. Further experiments will be necessary to determine whether the differences between normal and enucleated animals also reflect activity-dependent processes.

\section{Ocular Dominance in Visual Cortex}

The idea that thalamocortical afferents representing the right and left eyes in primary visual cortex segregate via Hebbian mechanisms into ocular dominance bands from an initially exuberant, overlapping projection had long been held as dogma in developmental neuroscience. This idea was based principally on two observations. First, transneuronal labeling of afferents from each eye by tritiated amino acids revealed a gradual increase in the segregation of label in primary visual cortex of cats and ferrets that coincided with the critical period for physiological ocular dominance plasticity (LeVay et al., 1978; Finney and Shatz,
1998; Ruthazer et al., 1999). This observation was accompanied by a single example in a young kitten of a labeled cortical axon of unknown origin that showed an unusually large arbor, extending over territory that would have included several ocular dominance columns (LeVay et al., 1978). Second, blockade of retinal activity by binocular TTX injections throughout the critical period left mature cats with unsegregated ocular dominance bands (Stryker and Harris, 1986). However, recent experiments by Crowley and Katz (2000) using more sensitive anatomical techniques have forced a re-examination of this idea. These authors found well-segregated ocular dominance columns in ferrets at a stage long before the onset of the critical period when completely overlapping inputs would have been expected based on the transneuronal studies. Furthermore they showed that surgical removal of one eye prior to this early stage did not cause a shift favoring the remaining eye during this early period of segregation.

The authors interpreted these results as evidence by default for early molecular specification of ocular dominance bands. An interesting prospect is that this putative molecular cue for ocular dominance bands may not be expressed in the thalamorecipient layer 4 of the cortex, but instead may be present in the subplate, a transient population of cortical neurons that are the first to receive thalamic innervation during development. Ablation of subplate neurons before the time of geniculocortical afferent segregation results in an unsegregated projection in mature animals (Ghosh and Shatz, 1992). Because subplate ablation also greatly reduces the ability of thalamic inputs to drive cortical activity (Kanold et al., 2003), it will be important to determine whether this results in a desegregation of initially segregated inputs during the critical period or if the afferents fail to segregate from the outset. Furthermore, the very realistic alternative explanation that, instead of molecular cues, early segregation of ocular dominance bands might rely on spontaneous activity patterns in the thalamocortical circuit independent of retinal drive (Weliky and Katz, 1999; Chiu and Weliky, 2002), cannot be explicitly excluded by any of these experiments.

A number of independent observations are, nonetheless, consistent with an activity-independent component to ocular dominance column formation. Thalamocortical projections in cats and ferrets both have a considerable bias favoring afferents that represent the contralateral eye (Law et al., 1988; Crair et al., 1998). If Hebbian mechanisms were exclusively responsible for ocular dominance column formation it is hard to imagine how ipsilateral eye patches could emerge from an initially intermingled set of afferents, given that they start with a marked disadvantage. 
Also, the layout of ocular dominance columns is predictably irregular in some species, including ferrets (Ruthazer et al., 1999; White et al., 1999) and minks (McConnell and LeVay, 1986), inconsistent with basic models of self-organization. Perhaps the most extreme example is the tree shrew, in which right and left eye inputs segregate into separate laminae in the cortex and are reportedly never commingled during development (Humphrey et al., 1977).

Furthermore, early binocular enucleation does not eliminate other aspects of the periodic "hypercolumnar" organization of visual cortex outside layer IV, including cytochrome oxidase blobs in primates (Kuljis and Rakic, 1990) and periodic long-range horizontal connections in ferrets (Ruthazer and Stryker, 1996). As these horizontal connections are patchy in monocular as well as binocular parts of visual cortex, they probably constitute an aspect of early cortical circuit organization independent of the ocular dominance columns. It is clear, however, that these systems are able to interact and modify each other in an activity-dependent manner during development (Lowel and Singer, 1992; Ruthazer and Stryker, 1996; Trachtenberg and Stryker, 2001; Chiu and Weliky, 2002). Until the putative molecules responsible for the periodic "hypercolumnar" structure of visual cortex, including ocular dominance, are identified, a purely activity-dependent mechanism for its development remains viable, but these recent data lend further credence to the possibility that such biochemical cues exist.

The tremendous degree of experience-dependent structural plasticity of ocular dominance bands during the so-called critical period, however, is not in dispute. Just 4 days of monocular deprivation at the critical period peak in kittens produces a dramatic shrinkage of arbors serving the deprived eye and changes in the nondeprived arbors can be detected several days later (Antonini and Stryker, 1993, 1996). This raises the question of why no change in the columns was detected by Crowley and Katz in response to monocular enucleation at much earlier stages. One possibility is that enucleation at this early developmental stage may be relatively ineffective at reducing ongoing spontaneous activity in the thalamocortical loop (Weliky and Katz, 1999). Alternatively, the cellular machinery for activity-dependent structural plasticity may not yet be present. The participation of later-maturing modulatory circuitry also may be required to detect differences in correlated activity. Evidence for this latter idea comes from experiments in which the onset of the critical period for physiological ocular dominance plasticity in mice is accelerated by forcing the early maturation of GABAergic circuitry (Huang et al., 1999; Fagiolini and Hensch, 2000).

Strabismus, which prevents conjugate binocular vision, results in ocular dominance columns that are more sharply delineated than occurs with normal visual experience (Shatz et al., 1977; Lowel, 1994). The functional purpose of experience-dependent plasticity with normal visual experience is, therefore, not to maximally segregate inputs, but rather to optimize the connections for proper processing of binocular vision. This is a valuable lesson to keep in mind when considering the role of activity in refining axonal projections in other systems. The most functionally precise circuit may not be the one that appears most anatomically refined.

\section{CONCLUSION}

Our detailed understanding of molecular and activitydependent mechanisms of map development in the retinotectal system should prove useful in guiding our thinking about how sensory maps form throughout the brain. In particular, a large body of evidence is emerging to support the idea that cooperation between chemoaffinity and correlation-based mechanisms, working simultaneously, but at different scales of map organization, is applicable in more areas of the CNS than previously believed.

\section{REFERENCES}

Alsina B, Vu T, Cohen-Cory S. 2001. Visualizing synapse formation in arborizing optic axons in vivo: dynamics and modulation by BDNF. Nat Neurosci 4:1093-1101.

Antonini A, Stryker MP. 1993. Rapid remodeling of axonal arbors in the visual cortex. Science 260:1819-1821.

Antonini A, Stryker MP. 1996. Plasticity of geniculocortical afferents following brief or prolonged monocular occlusion in the cat. J Comp Neurol 369:64-82.

Attardi D, Sperry R. 1963. Preferential selection of central pathways by regenerating optic fibers. Exp Neurology 7:46-64.

Ben-Ari Y. 2002. Excitatory actions of gaba during development: the nature of the nurture. Nat Rev Neurosci 3:728-739.

Boss VC, Schmidt JT. 1984. Activity and the formation of ocular dominance patches in dually innervated tectum of goldfish. J Neurosci 4:2891-2905.

Brown A, Yates PA, Burrola P, Ortuno D, Vaidya A, Jessell TM, Pfaff SL, O'Leary DD, Lemke G. 2000. Topographic mapping from the retina to the midbrain is controlled by relative but not absolute levels of EphA receptor signaling. Cell 102:77-88.

Chiu C, Weliky M. 2002. Relationship of correlated spon- 
taneous activity to functional ocular dominance columns in the developing visual cortex. Neuron 35:1123-1134.

Cline HT, Constantine-Paton M. 1989. NMDA receptor antagonists disrupt the retinotectal topographic map. Neuron 3:413-426.

Cline HT, Debski EA, Constantine-Paton M. 1987. NMDA receptor antagonist desegregates eye-specific stripes. Proc Natl Acad Sci USA 84:4342-4345.

Cohen-Cory S. 1999. BDNF modulates, but does not mediate, activity-dependent branching and remodeling of optic axon arbors in vivo. J Neurosci 19:9996-10003.

Coletti SM, Ide CF, Blankenau AJ, Meyer RL. 1990. Ocular dominance stripe formation by regenerated isogenic double temporal retina in Xenopus laevis. J Neurobiol 21: 276-282.

Constantine-Paton M, Law MI. 1978. Eye-specific termination bands in tecta of three-eyed frogs. Science 202:639641.

Crair MC, Gillespie DC, Stryker MP. 1998. The role of visual experience in the development of columns in cat visual cortex. Science 279:566-570.

Crowley JC, Katz LC. 2000. Early development of ocular dominance columns. Science 290:1321-1324.

Datwani A, Iwasato T, Itohara S, Erzurumlu RS. 2002. NMDA receptor-dependent pattern transfer from afferents to postsynaptic cells and dendritic differentiation in the barrel cortex. Mol Cell Neurosci 21:477-492.

Drescher U, Bonhoeffer F, Muller BK. 1997. The Eph family in retinal axon guidance. Curr Opin Neurobiol 7:75-80.

Easter SSJ, Stuermer CAO. 1984. An evaluation of the hypothesis of shifting terminals in the goldfish optic tectum. J Neurosci 4:1052-1063.

Fagiolini M, Hensch TK. 2000. Inhibitory threshold for critical-period activation in primary visual cortex. Nature 404:183-186.

Feldheim DA, Kim YI, Bergemann AD, Frisen J, Barbacid M, Flanagan JG. 2000. Genetic analysis of ephrin-A2 and ephrin-A5 shows their requirement in multiple aspects of retinocollicular mapping. Neuron 25:563-574.

Feldheim DA, Vanderhaeghen P, Hansen MJ, Frisen J, Lu Q, Barbacid M, Flanagan JG. 1998. Topographic guidance labels in a sensory projection to the forebrain. Neuron 21:1303-1313.

Finlay BL, Schneps SE, Schneider GE. 1979. Orderly compression of the retinotectal projection following partial tectal ablation in the newborn hamster. Nature 280:153155.

Finney EM, Shatz CJ. 1998. Establishment of patterned thalamocortical connections does not require nitric oxide synthase. J Neurosci 18:8826-8838.

Flanagan JG, Vanderhaeghen P. 1998. The ephrins and Eph receptors in neural development. Annu Rev Neurosci 21:309-345.

Fraser SE, Hunt RK. 1980. Retinotectal specificity: models and experiments in search of a mapping function. Annu Rev Neurosci 3:319-352.

Ghosh A, Shatz CJ. 1992. Involvement of subplate neurons in the formation of ocular dominance columns. Science 255:1441-1443.
Gnuegge L, Schmid S, Neuhauss SC. 2001. Analysis of the activity-deprived zebrafish mutant macho reveals an essential requirement of neuronal activity for the development of a fine-grained visuotopic map. J Neurosci 21: 3542-3548.

Grant P, Tseng Y. 1986. Embryonic and regenerating Xenopus retinal fibers are intrinsically different. Dev Biol 114:475-491.

Grubb MS, Rossi FM, Changeux JP, Thompson ID. 2003. Abnormal functional organization in the dorsal lateral geniculate nucleus of mice lacking the beta 2 subunit of the nicotinic acetylcholine receptor. Neuron 40:11611172 .

Grunwald IC, Korte M, Wolfer D, Wilkinson GA, Unsicker K, Lipp HP, Bonhoeffer T, Klein R. 2001. Kinase-independent requirement of EphB2 receptors in hippocampal synaptic plasticity. Neuron 32:1027-1040.

Harris WA. 1980. The effects of eliminating impulse activity on the development of the retinotectal projection in salamanders. J Comp Neurol 194:303-317.

Harris WA, Holt CE. 1995. From Tags to RAGS: chemoaffinity finally has receptors and ligands. Neuron 15:241244.

Hebb DO. 1949. The Organization of Behavior. New York: John Wiley and Sons. 368 p.

Hindges R, McLaughlin T, Genoud N, Henkemeyer M, O'Leary DD. 2002. EphB forward signaling controls directional branch extension and arborization required for dorsal-ventral retinotopic mapping. Neuron 35:475-487.

Huang L, Pallas SL. 2001. NMDA antagonists in the superior colliculus prevent developmental plasticity but not visual transmission or map compression. J Neurophysiol 86:1179-1194.

Huang ZJ, Kirkwood A, Pizzorusso T, Porciatti V, Morales B, Bear MF, Maffei L, Tonegawa S. 1999. BDNF regulates the maturation of inhibition and the critical period of plasticity in mouse visual cortex. Cell 98:739-755.

Huberman AD, Wang GY, Liets LC, Collins OA, Chapman B, Chalupa LM. 2003. Eye-specific retinogeniculate segregation independent of normal neuronal activity. Science 300:994-998.

Humphrey AL, Albano JE, Norton TT. 1977. Organization of ocular dominance in tree shrew striate cortex. Brain Res 134:225-236.

Ide CF, Fraser SE, Meyer RL. 1983. Eye dominance columns from an isogenic double-nasal frog eye. Science 221:293-295.

Iwasato T, Datwani A, Wolf AM, Nishiyama H, Taguchi Y, Tonegawa S, Knopfel T, Erzurumlu RS, Itohara S. 2000. Cortex-restricted disruption of NMDAR1 impairs neuronal patterns in the barrel cortex. Nature 406:726-731.

Johnson FA, Dawson AJ, Meyer RL. 1999. Activity-dependent refinement in the goldfish retinotectal system is mediated by the dynamic regulation of processes withdrawal: an in vivo imaging study. J Comp Neurol 406:548-562.

Kaethner RJ, Stuermer CA. 1992. Dynamics of terminal arbor formation and target approach of retinotectal axons in living zebrafish embryos: a time-lapse study of single axons. J Neurosci 12:3257-3271.

Kaethner RJ, Stuermer CAO. 1994. Growth behavior of retino- 
tectal axons in live zebrafish embryos under TTX-induced neuronal impulse blockade. J Neurobiology 25:781-796.

Kanold PO, Kara P, Reid C, Shatz CJ. 2003. Role of subplate neurons in functional maturation of visual cortical columns. Science 301:521-525.

Katz LC, Constantine-Paton M. 1988. Relationships between segregated afferents and postsynaptic neurons in the optic tectum of three-eyed frogs. J Neurosci 8:3160-3180.

Katz LC, Shatz CJ. 1996. Synaptic activity and the construction of cortical circuits. Science 274:1132-1138.

Knudsen EI, Zheng W, DeBello WM. 2000. Traces of learning in the auditory localization pathway. Proc Natl Acad Sci USA 97:11815-11820.

Kobayashi T, Nakamura H, Yasuda M. 1990. Disturbance of refinement of retinotectal projection in chick embryos by tetrodotoxin and grayanotoxin. Brain Res Dev Brain Res 57:29-35.

Kuljis RO, Rakic P. 1990. Hypercolumns in primate visual cortex can develop in the absence of cues from photoreceptors. Proc Natl Acad Sci USA 87:5303-5306.

Law MI, Constantine-Paton M. 1980. Right and left eye bands in frogs with unilateral tectal ablations. Proc Natl Acad Sci USA 77:2314-2318.

Law MI, Zahs KR, Stryker MP. 1988. Organization of primary visual cortex (area 17) in the ferret. J Comp Neurol 278:157-180.

LeVay S, Stryker MP, Shatz CJ. 1978. Ocular dominance columns and their development in layer IV of the cat's visual cortex. J Comp Neurol 179:223-244.

Lowel S. 1994. Ocular dominance column development: strabismus changes the spacing of adjacent columns in cat visual cortex. J Neurosci 14:7451-7468.

Lowel S, Singer W. 1992. Selection of intrinsic horizontal connections in the visual cortex by correlated neuronal activity. Science 255:209-212.

Mann F, Ray S, Harris W, Holt C. 2002. Topographic mapping in dorsoventral axis of the Xenopus retinotectal system depends on signaling through ephrin-B ligands. Neuron 35:461-473.

McConnell SK, LeVay S. 1986. Anatomical organization of the visual system of the mink, Mustela vison. J Comp Neurol 250:109-132.

McLaughlin T, Hindges R, O'Leary DD. 2003. Regulation of axial patterning of the retina and its topographic mapping in the brain. Curr Opin Neurobiol 13:57-69.

McLaughlin T, Torborg CL, Feller MB, O'Leary DD. 2003. Retinotopic map refinement requires spontaneous retinal waves during a brief critical period of development. Neuron 40:1147-1160.

Meyer RL. 1982. Tetrodotoxin blocks the formation of ocular dominance columns in goldfish. Science 218:589-591.

Meyer RL. 1983. Tetrodotoxin inhibits the formation of refined retinotopography in goldfish. Brain Res 282:293-298.

Meyer RL, Wolcott LL. 1988. Compression and expansion without impulse activity in the retinotectal projection of the goldfish. J Neurobiol 18:549-567.

Molnar Z, Lopez-Bendito G, Small J, Partridge LD, Blakemore C, Wilson MC. 2002. Normal development of embryonic thalamocortical connectivity in the absence of evoked synaptic activity. J Neurosci 22:10313-10323.
Muir-Robinson G, Hwang BJ, Feller MB. 2002. Retinogeniculate axons undergo eye-specific segregation in the absence of eye-specific layers. J Neurosci 22:5259-5264.

Olavarria JF, Hiroi R. 2003. Retinal influences specify cortico-cortical maps by postnatal day six in rats and mice. J Comp Neurol 459:156-172.

Olavarria JF, Li CP. 1995. Effects of neonatal enucleation on the organization of callosal linkages in striate cortex of the rat. J Comp Neurol 361:138-151.

O'Leary DD, Nakagawa Y. 2002. Patterning centers, regulatory genes and extrinsic mechanisms controlling arealization of the neocortex. Curr Opin Neurobiol 12:14-25.

Olson M, Meyer R. 1991. The effect of TTX-activity blockade and total darkness on the formation of retinotopy in the goldfish retinotectal projection. J Comp Neurol 303:412-423.

Olson M, Meyer R. 1994. Normal activity-dependent refinement in a compressed retinotectal projection in goldfish. J Comp Neurol 347:481-494.

O'Rourke NA, Cline HT, Fraser SE. 1994. Rapid remodeling of retinal arbors in the tectum with and without blockade of synaptic transmission. Neuron 12:921-934.

Penn AA, Riquelme PA, Feller MB, Shatz CJ. 1998. Competition in retinogeniculate patterning driven by spontaneous activity. Science 279:2108-2112.

Prakash N, Vanderhaeghen P, Cohen-Cory S, Frisen J, Flanagan JG, Frostig RD. 2000. Malformation of the functional organization of somatosensory cortex in adult ephrin-A5 knock-out mice revealed by in vivo functional imaging. J Neurosci 20:5841-5847.

Rajan I, Witte S, Cline HT. 1999. NMDA receptor activity stabilizes presynaptic retinotectal axons and postsynaptic optic tectal cell dendrites in vivo. J Neurobiol 38:357-368.

Rankin EC, Cook JE. 1986. Topographic refinement of the regenerating retinotectal projection of the goldfish in standard laboratory conditions: a quantitative WGA-HRP study. Exp Brain Res 63:409-420.

Reh T, Constantine-Paton M. 1984. Retinal ganglion cells change their projection sites during larval development of Rana pipiens. J Neurosci 4:442-457.

Reh T, Constantine-Paton M. 1985. Eye-specific segregation requires neural activity in three-eyed Rana pipiens. J Neurosci 5:1132-1143.

Rossi FM, Pizzorusso T, Porciatti V, Marubio LM, Maffei L, Changeux JP. 2001. Requirement of the nicotinic acetylcholine receptor beta 2 subunit for the anatomical and functional development of the visual system. Proc Natl Acad Sci USA 98:6453-6458.

Ruthazer ES, Akerman CJ, Cline HT. 2003. Control of Axon Branch Dynamics by Correlated Activity In Vivo. Science 301:66-70.

Ruthazer ES, Baker GE, Stryker MP. 1999. Development and organization of ocular dominance bands in primary visual cortex of the sable ferret. J Comp Neurol 407:151-165.

Ruthazer ES, Stryker MP. 1996. The role of activity in the development of long-range horizontal connections in area 17 of the ferret. J Neurosci 16:7253-7269.

Salin PA, Bullier J. 1995. Corticocortical connections in the visual system: structure and function. Physiol Rev 75: 107-154.

Schmidt J, Cicerone C, Easter S. 1978. Expansion of the 
half retinal projection to the tectum in goldfish: an electrophysiological and anatomical study. J Comp Neurol 177:257-278.

Schmidt J, Edwards D. 1983. Activity sharpens the map during the regeneration of the retinotectal projection in goldfish. Br Res 269:29-39.

Schmidt JT. 1985. Apparent movement of optic terminals out of a local postsynaptically blocked region in goldfish optic tectum. J Neurophysiol 53:237-251.

Schmidt JT, Buzzard M. 1993. Activity-driven sharpening of the retinotectal projection in goldfish: development under stroboscopic illumination prevents sharpening. J Neurobiol 24:384-399.

Shatz CJ. 1996. Emergence of order in visual system development. Proc Natl Acad Sci USA 93:602-608.

Shatz CJ, Lindstrom S, Wiesel TN. 1977. The distribution of afferents representing the right and left eyes in the cat's visual cortex. Brain Res 131:103-116.

Simon DK, Prusky GT, O'Leary DDM, Constantine PM. 1992. N-methyl-D-aspartate receptor antagonists disrupt the formation of a mammalian neural map. Proc Natl Acad Sci USA 89:10593-10597.

Smetters DK, Hahm J, Sur M. 1994. An N-methyl-Daspartate receptor antagonist does not prevent eye-specific segregation in the ferret retinogeniculate pathway. Brain Res 658:168-178.

Sperry RW. 1944. Optic Nerve Regeneration with Return of Vision in Anurans. J Neurophysiol 7:57-69.

Sperry RW. 1963. Chemoaffinity in the orderly growth of nerve fiber patterns and connections. Proc Natl Acad Sci USA 50:703-710.

Sretavan DW, Shatz CJ, Stryker MP. 1988. Modification of retinal ganglion cell axon morphology by prenatal infusion of tetrodotoxin. Nature 336:468-471.

Stellwagen D, Shatz CJ. 2002. An instructive role for retinal waves in the development of retinogeniculate connectivity. Neuron 33:357-367.

Stent GS. 1973. A physiological mechanism of Hebb's postulate of learning. Proc Natl Acad Sci USA 70:997-1001.

Straznicky C, Glastonbury J. 1979. Anomalous ipsilateral optic fibre projection in Xenopus induced by larval tectal ablation. J Embryol Exp Morphol 50:111-122.

Stryker MP, Harris WA. 1986. Binocular impulse blockade prevents the formation of ocular dominance columns in cat visual cortex. J Neurosci 6:2117-2133.

Stuermer CA. 1988. Trajectories of regenerating retinal axons in the goldfish tectum: I. A comparison of normal and regenerated axons at late regeneration stages. J Comp Neurol 267:55-68.

Takasu MA, Dalva MB, Zigmond RE, Greenberg ME.
2002. Modulation of NMDA receptor-dependent calcium influx and gene expression through EphB receptors. Science 295:491-495.

Tao HW, Zhang LI, Engert F, Poo M. 2001. Emergence of input specificity of ltp during development of retinotectal connections in vivo. Neuron 31:569-580.

Trachtenberg JT, Stryker MP. 2001. Rapid anatomical plasticity of horizontal connections in the developing visual cortex. J Neurosci 21:3476-3482.

Udin S, Gaze R. 1983. Expansion and retinotopic order in the goldfish retinotectal map after large retinal lesions. Exp Br Res 50:347-352.

Udin SB, Grant S. 1999. Plasticity in the tectum of Xenopus laevis: binocular maps. Prog Neurobiol 59:81-106.

Udvadia AJ, Koster RW, Skene JH. 2001. GAP-43 promoter elements in transgenic zebrafish reveal a difference in signals for axon growth during CNS development and regeneration. Development 128:1175-1182.

Walter J, Henke-Fahle S, Bonhoeffer F. 1987. Avoidance of posterior tectal membranes by temporal retinal axons. Development 101:909-913.

Weliky M, Katz LC. 1999. Correlational structure of spontaneous neuronal activity in the developing lateral geniculate nucleus in vivo. Science 285:599-604.

White LE, Bosking WH, Williams SM, Fitzpatrick D. 1999. Maps of central visual space in ferret V1 and V2 lack matching inputs from the two eyes. J Neurosci 19:7089-7099.

Witte S, Stier H, Cline HT. 1996. In vivo observations of timecourse and distribution of morphological dynamics in Xenopus retinotectal axon arbors. J Neurobiol 31:219-234.

Wong RO, Meister M, Shatz CJ. 1993. Transient period of correlated bursting activity during development of the mammalian retina. Neuron 11:923-938.

Wong WT, Myhr KL, Miller ED, Wong RO. 2000. Developmental changes in the neurotransmitter regulation of correlated spontaneous retinal activity. J Neurosci 20: 351-360.

Yates PA, Roskies AL, McLaughlin T, O'Leary DD. 2001. Topographic-specific axon branching controlled by ephrin-As is the critical event in retinotectal map development. J Neurosci 21:8548-8563.

Zhang LL, Tao HW, Holt CE, Harris WA, Poo M-M. 1998. A critical window for cooperation and competition among developing retinotectal synapses. Nature 395:37-44.

Zhou ZJ, Zhao D. 2000. Coordinated transitions in neurotransmitter systems for the initiation and propagation of spontaneous retinal waves. J Neurosci 20:6570-6577.

Ziv NE, Smith SJ. 1996. Evidence for a role of dendritic filopodia in synaptogenesis and spine formation. Neuron 17:91-102. 